\title{
Prevalence of Toxocara and Toxascaris infection among human and animals in Iran with meta-analysis approach
}

\author{
Aida Vafae Eslahi ${ }^{1 \dagger}$, Milad Badri ${ }^{1 \dagger}$, Ali Khorshidi ${ }^{2}$, Hamidreza Majidiani ${ }^{1}$, Elham Hooshmand ${ }^{3}$, Hamid Hosseini ${ }^{4}$, \\ Ali Taghipour ${ }^{1}$, Masoud Foroutan ${ }^{5}$, Nader Pestehchian ${ }^{6,7}$, Farzaneh Firoozeh ${ }^{8}$, Seyed Mohammad Riahi ${ }^{9 \dagger}$ and \\ Mohammad Zibaei ${ }^{4,10^{*}}$ iD
}

\begin{abstract}
Background: Toxocariasis is a worldwide zoonotic parasitic disease caused by species of Toxocara and Toxascaris, common in dogs and cats. Herein, a meta-analysis was contrived to assess the prevalence of Toxocara/Toxascaris in carnivore and human hosts in different regions of Iran from April 1969 to June 2019.

Methods: The available online articles of English (PubMed, Science Direct, Scopus, and Ovid) and Persian (SID, Iran Medex, Magiran, and Iran Doc) databases and also the articles that presented in held parasitology congresses of Iran were involved.

Results: The weighted prevalence of Toxocara/Toxascaris in dogs (Canis familiaris) and cats (Felis catus) was 24.2\% (95\% Cl: 18.0-31.0\%) and 32.6\% (95\% Cl: 22.6-43.4\%), respectively. Also, pooled prevalence in jackal (Canis aureus) and red fox (Vulpes vulpes) was 23.3\% (95\% Cl: 7.7-43.2\%) and 69.4\% (95\% Cl: 60.3-77.8\%), correspondingly. Weighted mean prevalence of human cases with overall 28 records was 9.3\% (95\% Cl: 6.3-13.1\%). The weighted prevalence of Toxocara canis, Toxocara cati, and Toxascaris leonina was represented as 13.8\% (95\% Cl: 9.8-18.3\%), 28.5\% (95\% Cl: 20-37.7\%) and 14.3\% (95\% Cl: 8.1-22.0\%), respectively.

Conclusion: Our meta-analysis results illustrate a considerable prevalence rate of Toxocara/Toxascaris, particularly in cats and dogs of northern parts of Iran. The presence of suitable animal hosts, optimum climate and close contact of humans and animals would have been the reason for higher seroprevalence rates of human cases in our region. Given the significance clinical outcomes of human Toxocara/Toxascaris, necessary measures should be taken.
\end{abstract}

Keywords: Systematic review, Meta-analysis, Toxocariasis, Toxocara canis, Toxocara cati, Toxascaris leonina, Iran

\section{Background}

Zoonoses are those complications which are transmissible between human and animal populations [1]. In this regard dogs and cats are considered as a public health concern, as they may harbor various pathogens such as zoonotic helminths including Toxocara species [2]. Toxocariasis is a worldwide parasitic infection, primarily

\footnotetext{
* Correspondence: zibaeim@sums.ac.ir

${ }^{\dagger}$ Aida Vafae Eslahi, Milad Badri and Seyed Mohammad Riahi contributed equally to this work.

${ }^{4}$ Department of Parasitology and Mycology, School of Medicine, Alborz University of Medical Sciences, 3149779453, Karaj, Iran

${ }^{10}$ Evidence-based Phytotherapy and Complementary Medicine Research Center, Alborz University of Medical Sciences, Karaj, Iran

Full list of author information is available at the end of the article
}

rendered by $T$. canis in dogs, $T$. cati in cats and foxes and T. leonina in a wide range of carnivores [3]. Mature worms lay eggs in the intestinal lumen of their host, which are excreted into the environment via defecation and pass their developmental stages in optimum soil and climate conditions. Upon ingestion of embryonated eggs by another host, the larvae would emerge and invade the intestinal mucosa, then migrate through viscera such as lungs, liver, and kidneys. In addition, transplacental and transmammary transmission to puppies and kittens are important routes of infection. In an epidemiological perspective, animal hosts parasitized by adult worms in their gut can disseminate infection by shedding parasite eggs into environment [4]. In an epidemiological

(c) The Author(s). 2020 Open Access This article is distributed under the terms of the Creative Commons Attribution 4.0 International License (http://creativecommons.org/licenses/by/4.0/), which permits unrestricted use, distribution, and reproduction in any medium, provided you give appropriate credit to the original author(s) and the source, provide a link to the Creative Commons license, and indicate if changes were made. The Creative Commons Public Domain Dedication waiver (http://creativecommons.org/publicdomain/zero/1.0/) applies to the data made available in this article, unless otherwise stated. 
perspective, animal hosts parasitized by adult worms in their gut, can shed parasite eggs, hence considered as a source for dissemination of the infection [5]. Human infection occurs by accidental ingestion of eggs, and, to a lesser extent, via pica and devouring on the paratenic hosts, including chicken, cattle, lamb, pig, and earthworms $[4,6]$. Consequently, developmentally-arrested larvae migrate through body organs, but don't develop into mature worms; hence, they provoke an array of syndromes enclosing VLM, NLM, and OLM as well as covert infection and asymptomatic toxocariasis [7-9]. Although rare, cardiac-associated toxocariasis is a serious, life-threatening complication due to VLM which has recently been emphasized [10].

Most of the infected individuals manifest nonspecific symptoms such as a cough, rhonchus, dyspnea and pyrexia along with hepatomegaly and eosinophilic granuloma, which implicates diagnosis of the infection using more sensitive approaches such as immunological assays i.e., ELISA for screening and Western blot for confirmation, rather than histological or parasitological methods [4, 11].

Toxocariasis cause by $T$. cati and $T$. canis frequently impacts young cats and dogs from birth to 1 year old, entailing respiratory signs (coughing due to pulmonary larval migration), general failure to thrive (retarded growth, emaciation, debilitated body coat and arthralgia) and intestinal disorders (alternating diarrhea and constipation, pot-belly and vomiting). No remarkable trait is seen following Toxascaris infection in dogs and/or cats and it is usually well-tolerated [3-5].

One of the characteristic of helminthic parasites is the stimulation of the immune system that leads to increased Th2 response and high production of IL-4, IL-5, IL-9, IL-10, IL-13, eosinophils, and IgE. Toxocara larvae can causes severe hyper eosinophilia and allergic involvements with effect on IgE and IL-5. Consequently, the production of specific antibodies provides the most complete evidence for Toxocara infection, which is the base of diagnostic tests such as ELISA and Western blot for reactivity to larval TES antigen [11-13].

Iran, a Middle Eastern country, possesses several climatological areas with particular characteristics in each region; this would have a significant bias on the epidemiology of Toxocara/Toxascaris species. In the previous studies the infection of dogs and cats with Toxocara species in different parts of Iran has been shown [14]. Despite the prevalence of Toxocara canis in the most areas, molecular studies on cat nematodes in Shiraz, in south-central Iran showed that, the most prevalent one is $T$. cati [15]. Toxocara vitulorum is frequently found in ruminants. Its main hosts are cattle and buffalo in tropical and sub-tropical regions [16]. It has been reported that $16 \%$ (95\% CI: $11-21 \%$; 470 out of 3031 samples) of soil samples gathered from public parks of the Iran were positive for Toxocara spp. eggs [17].

On the other hand, due to increasing body of work on Toxocara prevalence in various human/animal hosts in Iran, a comprehensive review would be exceedingly beneficial for appraising progresses about this zoonosis. Therefore, this meta-analysis attempts to fill the current gaps and provides insights into parasite prevalence with respect to host type, Toxocara and Toxascaris species, and geographical region in the country.

\section{Methods \\ Study area}

Iran has a population of approximately 80 million (as of 2015), and is located between $25^{\circ} 3$ and $39^{\circ} 47 \quad \mathrm{~N}$ and $44^{\circ} 5$ and $63^{\circ} 18$ E, which covers a wide territory in the Middle East area $(1,648,195 \mathrm{~km} 2)$. The country borders Afghanistan and Pakistan to the east, Iraq and Turkey to the west, the Persian Gulf and Oman Sea to the south, and Azerbaijan, Armenia, and Turkmenistan to the north. The Iranian plateau climate is generally hot and dry, however the Caspian Sea coast in northern parts, comprising Golestan, Mazandaran and Guilan provinces, is Mediterranean-like, demonstrating heavy rainfalls, vegetation-enriched, surrounded by dense forests and a diverse range of carnivorous animals These geo-ecological features would provide a well-established setting for most parasites, e.g. soil-transmitted helminthiases, to localize in the area and parasitize many canid species. Also, the country is a mountainous region with several mountain ranges, mostly located at the western and northern parts such as Zagros mountain ranges with colder winters and heavy snowfalls. The annual precipitation is $680 \mathrm{~mm}$ in the eastern part of the plain and more than $1700 \mathrm{~mm}$ in the western parts [18-21].

\section{Search strategy}

The PRISMA protocol (preferred reporting items for systematic reviews and meta-analysis) was employed to conduct this meta-analysis [22]. In order to assess the prevalence of $T$. canis, $T$. cati and T. leonina in humans and carnivores of different parts of Iran, we investigated the available online articles of both Persian (SID, Iran Medex, Magiran, Iran Doc) and English (PubMed, Science Direct, Scopus, Ovid) databases. The search include between April 1969 and June 2019. Also, the articles that presented in held Parasitology congresses of Iran were involved. A combination of the following search terms were employed in our literature searches as follows: "Toxocariasis" OR "Toxocara infection" OR "Toxocara canis" OR "Toxocara cati" OR "Toxascaris leonina") AND ("Carnivora" OR "Human") AND ("Prevalence" OR "Epidemiology") AND ("Iran"). 


\section{Study selection and data extraction}

After hand searching in bibliographic list of obtained full-text records for any related literature as well as removing duplicates, two independent reviewers screened the titles and abstracts for initial inclusion. A third reviewer was also involved for consensus in the case of any disagreements. Finally, those records that met the following inclusion criteria were eligible to enter our meta-analysis: (A) Peer-reviewed originally-published papers both in English or Persian; (B) Being available online between April 1969 till June 2019; (C) Crosssectional investigations that assessed the prevalence of Toxocara spp. in various carnivores and human populations in Iran; (D) Studies that detected Toxocara infection using at least one of the parasitological, serological and molecular methods; (e) exact total sample size, positive samples and the respective prevalence rates were available. Empirical studies and any kind of review papers were excluded and failed for further analysis. A detailed variable of each of articles, including: province, year of publication, study design, sample size, detection method, and prevalence rates, in addition to animal species and sampling method for animal-based investigations were gathered. In this study, the JBI critical appraisal checklist for prevalence studies was employed [23].

\section{Study quality assessment}

The JBI checklist was used for quality assessment of the included articles. This checklist contains eight questions with four options including, Yes, No, Unclear, and Not applicable (Additional file 1: Figure S1). Briefly, a study can be awarded a maximum of one star for each numbered item. The papers with a total score of $\leq 6$ and $\geq 7$
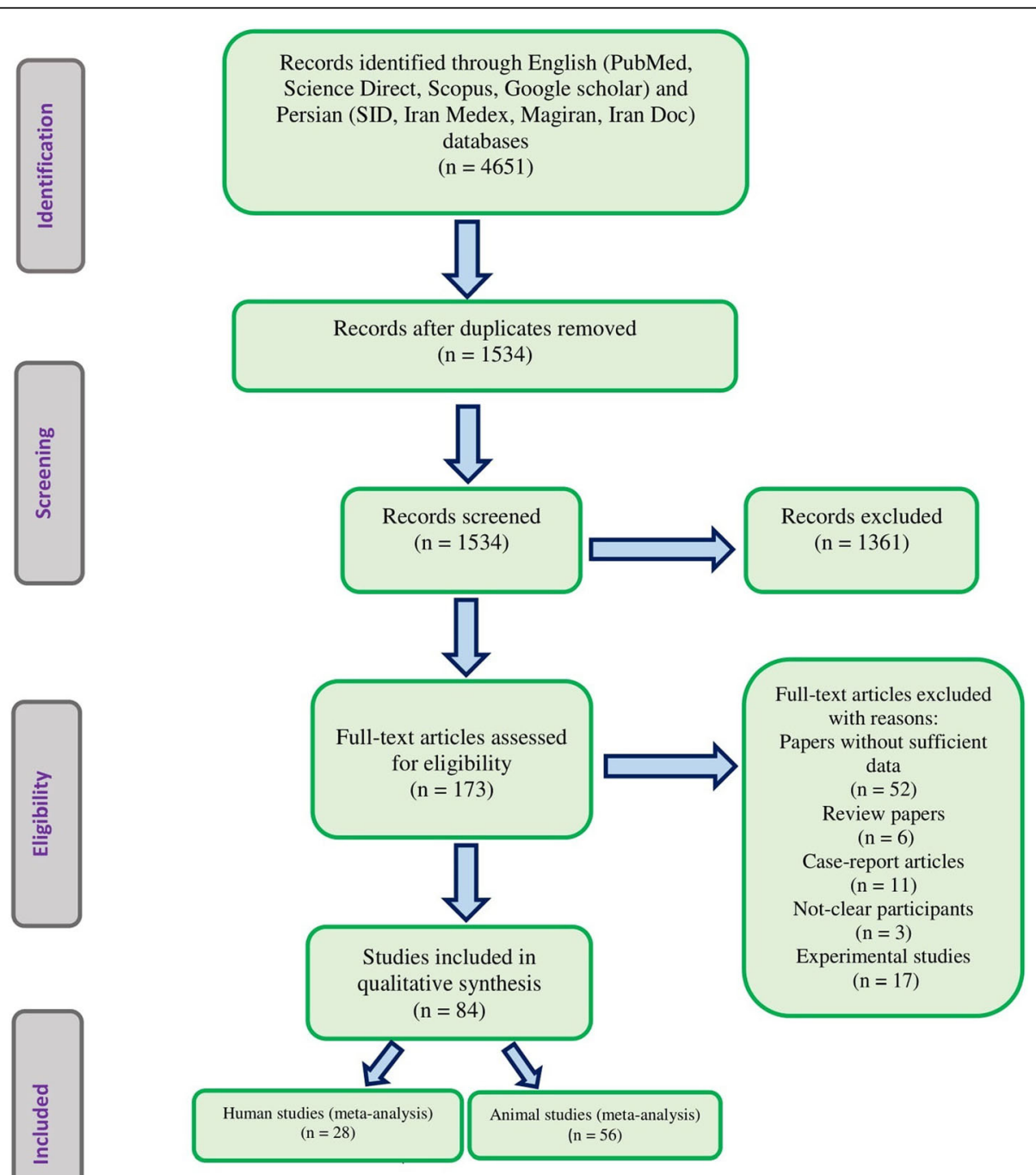

Fig. 1 Flowchart describing the study design process 
points were specified as the moderate and high quality, respectively. Based on the obtained score, the authors have decided to include and exclude the papers [23].

\section{Meta-analysis}

Briefly, meta-analysis was yielded as a forest plot representing the prevalence estimates and related confidence intervals of each study along with summary measures. Also, the heterogeneity was analyzed using STATA statistical software (Version 8.2) to calculate Cochran's $\mathrm{Q}$ and $\mathrm{I}^{2}$ statistics. $\mathrm{I}^{2}$ values of 25,50 , and $75 \%$ were considered as low, moderate and high heterogeneity, respectively [24]. Furthermore, the funnel plot based on Egger's regression test illustrates publication bias and small study effects. In the current study, $\mathrm{I}^{2}$ was substantial; therefore, we used a random effects model at a 95\% $\mathrm{CI}$, to give a more conservative estimate of the Toxocara infection prevalence.

Table 1 Pooled prevalence of Toxocara infection among human and animals in Iran

\begin{tabular}{|c|c|c|c|c|c|c|c|}
\hline Toxocara/Toxascaris & \# of study & Total sample size & Positive & Pooled prevalence (95\% Cl) & Q & df & $1^{2}$ \\
\hline \multicolumn{8}{|l|}{ Human part } \\
\hline National Prevalence & 28 & 11,377 & 1367 & $9.3(6.1-13.1)$ & 1114.7 & 27 & 97.6 \\
\hline \multicolumn{8}{|l|}{ Quality grade } \\
\hline high & 18 & 7597 & 812 & $10.0(5.9-15.0)$ & 743.7 & 17 & 97.7 \\
\hline moderate & 10 & 3780 & 555 & $8.1(3.3-14.7)$ & 322.3 & 9 & 97.2 \\
\hline \multicolumn{8}{|l|}{ Publication Year } \\
\hline 2000-2005 & 2 & 583 & 146 & $24.9(21.4-28.5)$ & 1114.1 & 1 & 99.9 \\
\hline 2005-2010 & 5 & 2939 & 391 & $9.9(2.3-21.6)$ & 285.9 & 4 & 98.6 \\
\hline 2010-2015 & 8 & 1477 & 165 & $8.6(1.9-19.3)$ & 240.3 & 7 & 97.1 \\
\hline 2015-2019 & 13 & 6378 & 665 & $8.0(4.2-12.7)$ & 471.5 & 12 & 97.5 \\
\hline \multicolumn{8}{|l|}{ Animal part } \\
\hline Prevalence in Dog & 29 & 4065 & 844 & $24.2(18.0-31.0)$ & 100.1 & 28 & 95.2 \\
\hline Prevalence in Cat & 20 & 1670 & 511 & $32.6(22.6-43.4)$ & 386.9 & 19 & 95.1 \\
\hline Prevalence in Jackal & 4 & 57 & 13 & $23.3(7.7-43.2)$ & 6.9 & 3 & 56.5 \\
\hline Prevalence in Red fox & 2 & 111 & 76 & $69.4(60.3-77.8)$ & - & - & - \\
\hline Wild cat & 1 & 8 & 5 & $62.5(24.5-91.5)$ & - & - & - \\
\hline \multicolumn{8}{|c|}{ Parasite species in carnivores } \\
\hline T. canis (overall) & 31 & 4420 & 545 & $13.8(9.8-18.3)$ & 449.2 & 30 & 93.3 \\
\hline \multicolumn{8}{|l|}{ Publication Year } \\
\hline$>2005$ & 4 & 368 & 17 & $5.0(0.6-12.5)$ & 19.1 & 3 & 84.3 \\
\hline 2005-2010 & 6 & 638 & 159 & $26.7(12.8-43.3)$ & 95.9 & 5 & 94.8 \\
\hline 2010-2015 & 14 & 2638 & 290 & $13.1(7.8-19.4)$ & 204.7 & 13 & 93.6 \\
\hline 2015-2019 & 7 & 776 & 79 & $11.0(6.2-16.9)$ & 27.1 & 6 & 77.8 \\
\hline T. cati (overall) & 24 & 1811 & 503 & $28.5(20.0-37.7)$ & 394.7 & 23 & 94.2 \\
\hline \multicolumn{8}{|l|}{ Publication Year } \\
\hline$>2005$ & 3 & 221 & 95 & $45.3(26.8-64.4)$ & 11.2 & 2 & 82.1 \\
\hline 2005-2010 & 10 & 792 & 230 & $28.6(18.0-40.6)$ & 112.1 & 9 & 92.0 \\
\hline 2010-2015 & 7 & 520 & 98 & $21.6(8.0-39.3)$ & 112.3 & 6 & 94.7 \\
\hline 2015-2019 & 4 & 278 & 80 & $28.9(3.0-66.2)$ & 105.2 & 3 & 97.1 \\
\hline T. leonina (overall) & 20 & 3150 & 420 & $14.3(8.1-22.0)$ & 498.4 & 19 & 96.2 \\
\hline \multicolumn{8}{|l|}{ Publication Year } \\
\hline$>2005$ & 2 & 220 & 81 & $36.0(29.7-42.5)$ & 498.4 & 1 & 99.8 \\
\hline 2005-2010 & 3 & 329 & 48 & $12.1(0.8-32.5)$ & 42.4 & 2 & 95.3 \\
\hline 2010-2015 & 11 & 2032 & 175 & $12.2(4.6-22.6)$ & 253.0 & 10 & 96.0 \\
\hline 2015-2019 & 4 & 562 & 98 & $13.4(4.9-25.0)$ & 30.4 & 3 & 90.1 \\
\hline
\end{tabular}




\section{Results}

\section{Hosts}

Following systematic search of eight databases, totally 28 records human studies and 56 animal investigations were found eligible regarding Toxocara/Toxascaris (Fig. 1). During a 19-years period, 11,781 human individuals were examined and the calculated weighted prevalence was 9.3\% (95\% CI: 6.1-13.1\%) (Tables 1 and 2). The trend line of human Toxocara/Toxascaris infection demonstrated that the prevalence has declined in spite of increased bulk of work on human population (Additional file 2: Figure S2). Most records (10 studies) were conducted in both rural and urban circumstances, however seroprevalence was mostly predominant in urban regions with 14\% (95\% CI: 5.6-25.3\%) (No showed data).
People under 20 years old were mostly examined by serodiagnosis approach, indicating 8.2\% (95\% CI: 4.6$12.7 \%$ ) seroprevalence rate (Additional file 3: Figure S3).

A number of 29 entries contributed to prevalence of Toxocara/Toxascaris in dogs (Canis familiaris), showing a prevalence of $24.2 \%$ (95\% CI: $18.0-31.0 \%)$. The weighted prevalence of Toxocara/Toxascaris was higher in 20 investigations which examined cats (Felis catus) [32.6\% (95\% CI: 22.6-43.4\%)] (Tables 1 and 3). Interestingly, one study also used serodiagnosis in cats indicating a $53.8 \% \quad(95 \%$ CI: $39.5-67.8 \%)$ seroprevalence (Additional file 4: Figure S4).

Four studies (all necropsy-based) dedicated to prevalence of Toxocara/Toxascaris in jackal (Canis aureus), representing a $23.3 \%(95 \% \mathrm{CI}: 7.7-43.2 \%)$ frequency. A

Table 2 Baseline characteristics of included studies for human toxocariasis in Iran

\begin{tabular}{|c|c|c|c|c|c|c|c|c|c|c|}
\hline \multirow[t]{2}{*}{ Author(s) } & \multirow[t]{2}{*}{ Country } & \multirow{2}{*}{$\begin{array}{l}\text { Publication } \\
\text { year }\end{array}$} & \multirow{2}{*}{$\begin{array}{l}\text { Sample } \\
\text { size }\end{array}$} & \multicolumn{3}{|c|}{$\mathrm{Dm}^{\mathrm{a}}$} & \multirow[t]{2}{*}{$\mathrm{P}^{\mathrm{e}}[\mathrm{N}(\%)]$} & \multicolumn{3}{|l|}{$S M^{f}$} \\
\hline & & & & $\overline{P^{b}}$ & $S^{c}$ & $M^{d}$ & & ELISA $^{\mathrm{g}}$ & $W B^{h}$ & $\mathrm{IFAT}^{\mathrm{i}}$ \\
\hline S. M. Sadjjadi & Shiraz & 2000 & 519 & & * & & $133(25.60)$ & * & & \\
\hline H. Yousefi & Chaharmahal-Va Bakhtiari & 2001 & 64 & & $*$ & & $13(20.31)$ & & & $*$ \\
\hline L. Akhlaghi & Kermanshah & 2006 & 260 & & * & & $22(8.46)$ & * & & \\
\hline M. Fallah & Hamadan & 2007 & 544 & & * & & $29(5.30)$ & * & & \\
\hline A. Nourian & Zanjan & 2007 & 810 & & * & & $22(2.70)$ & * & & \\
\hline S. M. Alavi & Khuzestan & 2008 & 115 & & $*$ & & $16(13.9)$ & * & & \\
\hline M. Sharif & Mazandaran & 2010 & 1210 & & $*$ & & $302(25.00)$ & * & & \\
\hline S. M. Alavi & Khuzestan & 2011 & 203 & & * & & $4(2.00)$ & * & & \\
\hline Kh. Agin & Tehran & 2012 & 89 & & $*$ & & $14(16.00)$ & * & & \\
\hline M. Zibaei & Lorestan & 2013 & 85 & & $*$ & & $3(3.50)$ & $*$ & * & \\
\hline Y. Gharedaghi & East Azerbaijan & 2014 & 336 & & * & & 99 (29.46) & * & & \\
\hline Sh. Khademvatan & Khuzestan & 2014 & 95 & & * & & $4(4.30)$ & $*$ & * & \\
\hline M. Zibaei & Shiraz & 2015 & 98 & & * & & $33(33.67)$ & * & * & \\
\hline A. Hosseini Safa & Isfahan & 2015 & 427 & & $*$ & & $6(1.39)$ & $*$ & & \\
\hline S. Allahdin & Khuzestan & 2015 & 144 & & $*$ & & $2(1.38)$ & * & * & \\
\hline F. Berenji & Khorasan & 2016 & 93 & & $*$ & & $1(1.07)$ & $*$ & & \\
\hline T. Momeni & West Azerbaijan & 2016 & 397 & & * & & $12(3.00)$ & $*$ & & \\
\hline M. Kh. Shahraki & Sistan and Baluchestan & 2017 & 364 & & $*$ & & $14(3.8)$ & $*$ & & \\
\hline H. Mahmoudvand & Lorestan & 2018 & 316 & & * & & $14(4.40)$ & $*$ & & \\
\hline S. Shokouhi & Ilam & 2018 & 383 & & $*$ & & $84(22.00)$ & * & & \\
\hline M. Beiromvand & Khuzestan & 2018 & 400 & & $*$ & & $11(2.70)$ & * & & \\
\hline Z. Baghani & Tehran & 2018 & 374 & & $*$ & & $21(5.60)$ & * & & \\
\hline S. Khoshnood & Ilam & 2018 & 300 & & $*$ & & $35(11.70)$ & * & & \\
\hline S. Ashtari & Urmia & 2018 & 1002 & & * & & $172(17.22)$ & $*$ & & \\
\hline B. Sarkari & Shiraz & 2018 & 617 & & $*$ & & $39(6.30)$ & $*$ & & \\
\hline S. Aghamolaie & Mazandaran & 2018 & 630 & & $*$ & & $148(23.50)$ & $*$ & & \\
\hline V. Raissi & Ilam & 2018 & 539 & & * & & 97 (17.99) & * & & \\
\hline M. K. Shahraki & Sistan and Baluchestan & 2019 & 963 & & * & & $17(1.70)$ & * & & \\
\hline
\end{tabular}

${ }^{\mathrm{a}}$ Detection method, ${ }^{\mathrm{b}}$ Parasitology, ${ }^{\mathrm{c}}$ Serology, ${ }^{\mathrm{d}}$ Molecular, ${ }^{\mathrm{e}}$ Prevalence, ${ }^{\mathrm{f}}$ Serological method, ${ }^{\mathrm{g}}$ Enzyme-linked immunosorbent assay, ${ }^{\mathrm{h}}$ Western blot, ${ }^{\mathrm{i}}$ Indirect fluorescent antibody test 


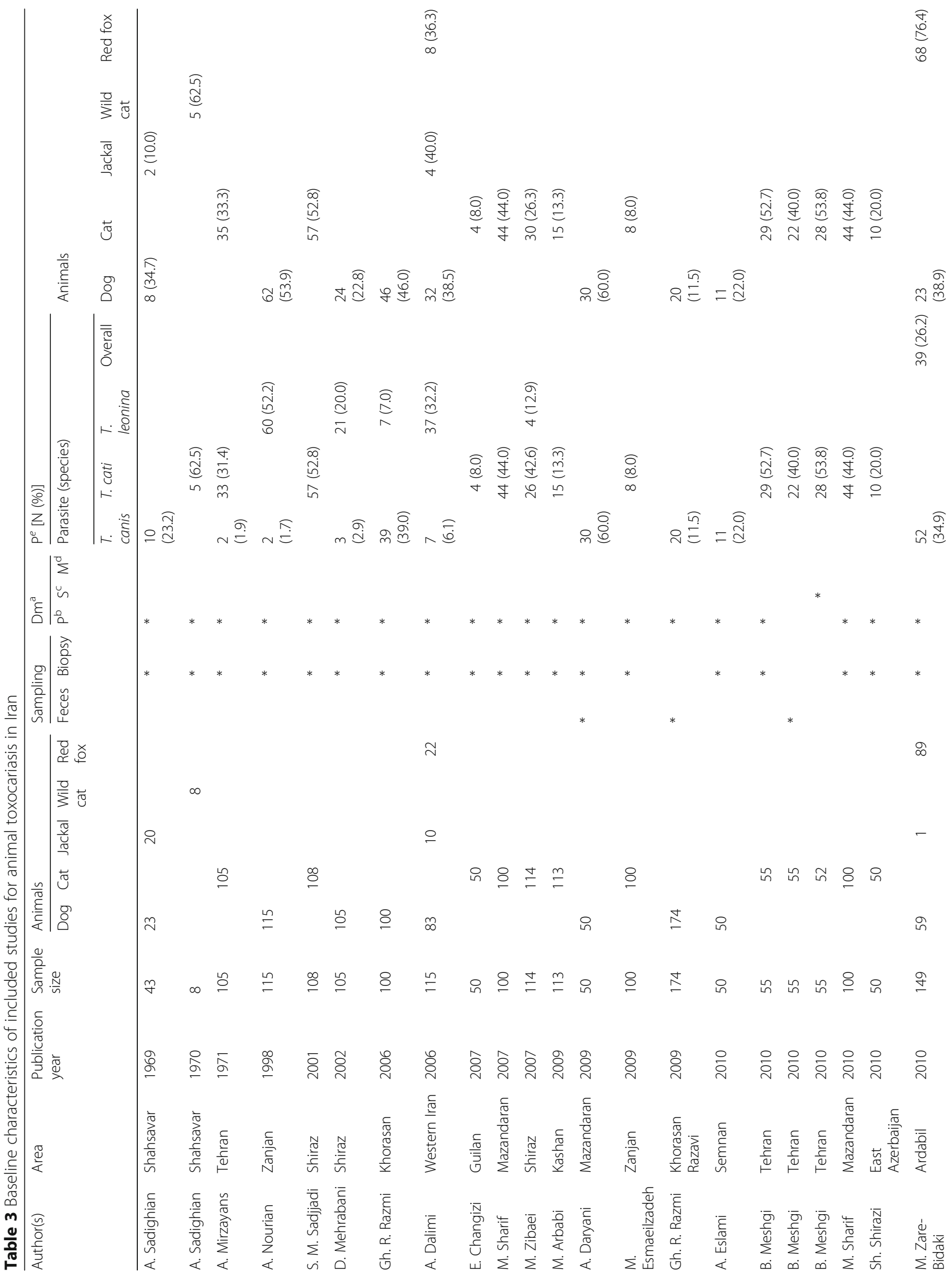


Eslahi et al. BMC Infectious Diseases

(2020) $20: 20$

Page 7 of 17

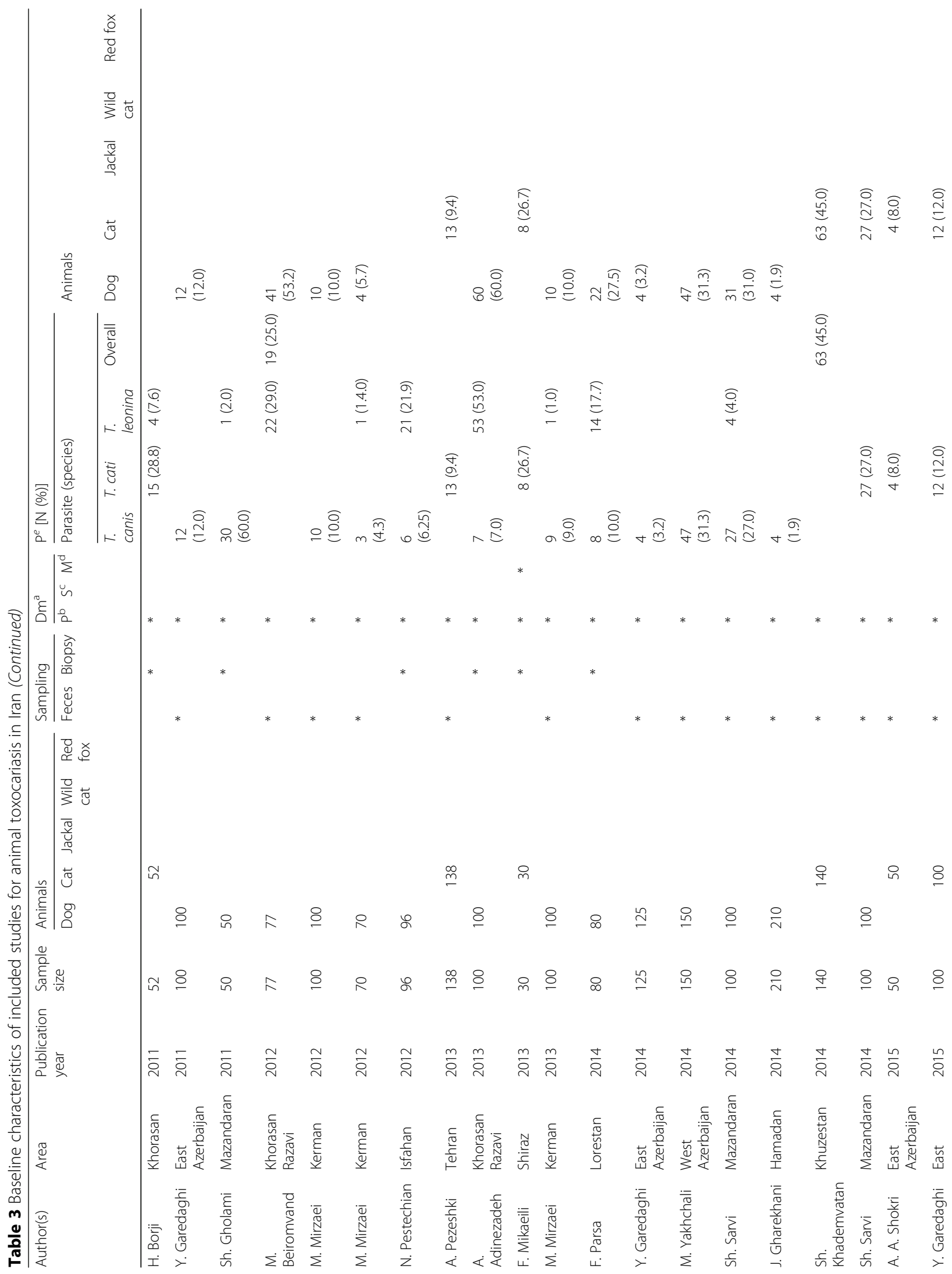




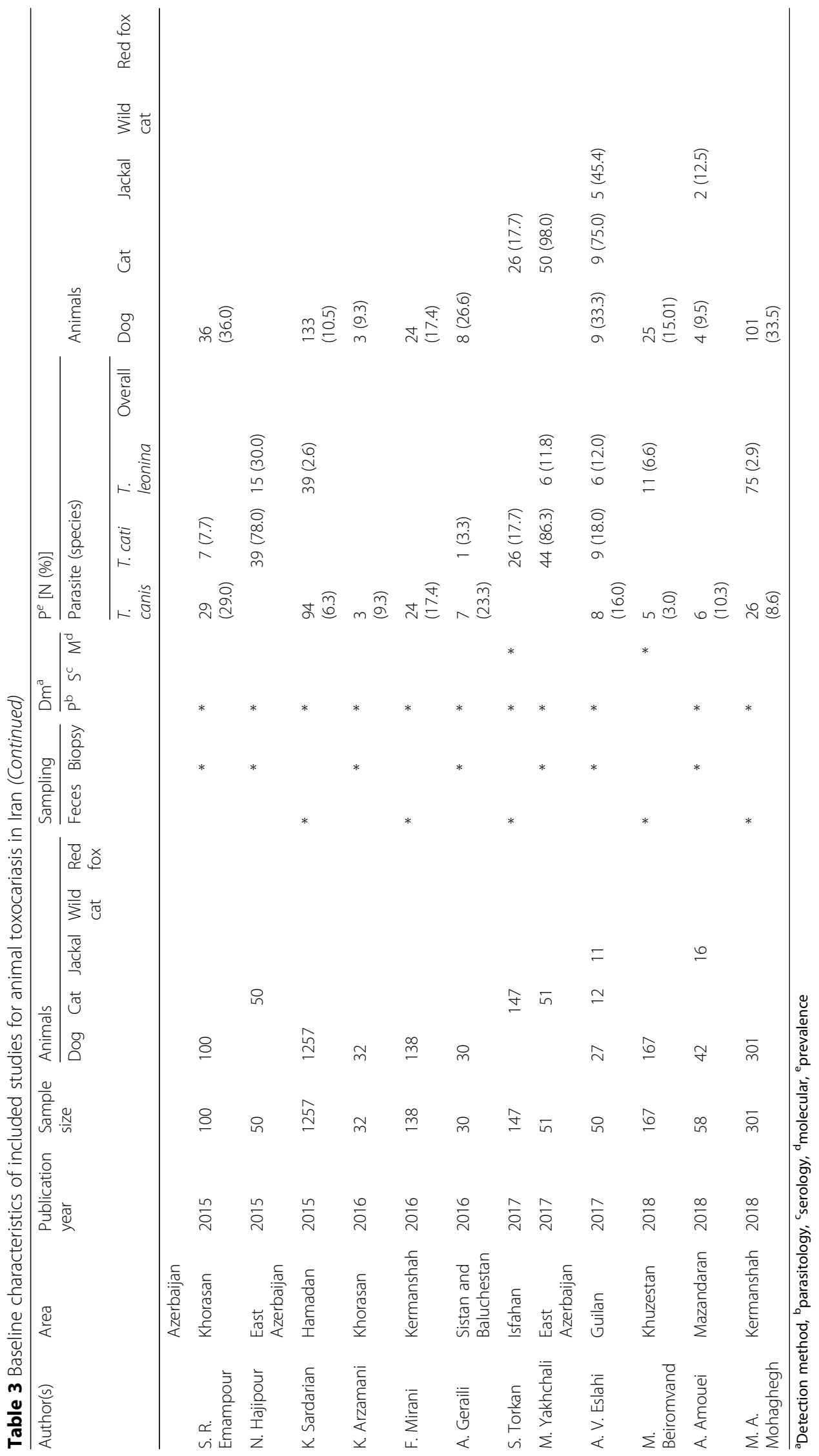


high prevalence among examined carnivores in Iran was observed in two studies of red fox (Vulpes vulpes) with 69.4\% (95\% CI: $60.3-77.8 \%$ ) and one study of wildcat (Felis silvestris) with 62.5\% (95\% CI: 24.5-91.5\%) (Tables 1 and 3).

According to the detection method, the highest total prevalence of $T$. canis in feces was related to the formalin-ether method [10.5\% (95\% CI: 5.8-16.3\%)] (Additional file 5: Figure S5). Also the most total prevalence of $T$. cati in feces was related to the formalin-ether method [13.4\% (95\% CI: 9.7-17.7\%)] (Additional file 6: Figure S6).

\section{Parasite species}

Among Toxocara/Toxascaris species examined through included studies in Iran, $T$. cati possessed the highest prevalence rate with $28.5 \%$ (95\% CI: 20.0-37.7\%) (25 records), whereas the pooled prevalence of $T$. leonina (20 records) and T. canis (31 records) infections were 14.3\% (95\% CI: 8.1-22.0\%) and 13.8\% (95\% CI: 9.8$18.3 \%$ ), respectively (Figs. 2, 3 and 4 and Table 3 ). Necropsy was the method of choice for detection Toxocara/Toxascaris spp., implicating in 31.3\% (95\% CI: 20.6-43.0\%) prevalence of T. cati, $18.8 \%$ (95\% CI: $10.2-$
29.1\%) frequency of T. leonina, and $17.2 \%$ (95\% CI: $9.8-$ 26.1\%) prevalence of T. canis (Figs. 5, 6 and 7).

\section{Geographical characteristics}

There was no statistically significant association between the estimated pooled prevalence of Toxocara/Toxascaris infection in human population and mean temperature $(P=0.49)$, humidity $(P=0.49)$, longitude $(P=0.7)$, and latitude $(P=0.27)$. Among three parasite species, only humidity $(P=0.023)$ and latitude $(P=0.032)$ for $T$. canis were statistically significant, while others were not remarkably involved (Fig. 8).

\section{Discussion}

The current systematic review and meta-analysis was aimed to elucidate the prevalence of Toxocara spp. infection in animal and human hosts in Iran. The human infection was highly concentrated in two northern provinces (Mazandaran and East Azerbaijan) (Fig. 9), highlighting optimum geo-ecological milieu in those parts of the country because of high percentage humidity due to vicinity to the Caspian Sea as well as considerable rainfall during the year; notwithstanding, we didn't found any statistically significant correlation between human Toxocara/Toxascaris seroprevalence studies and

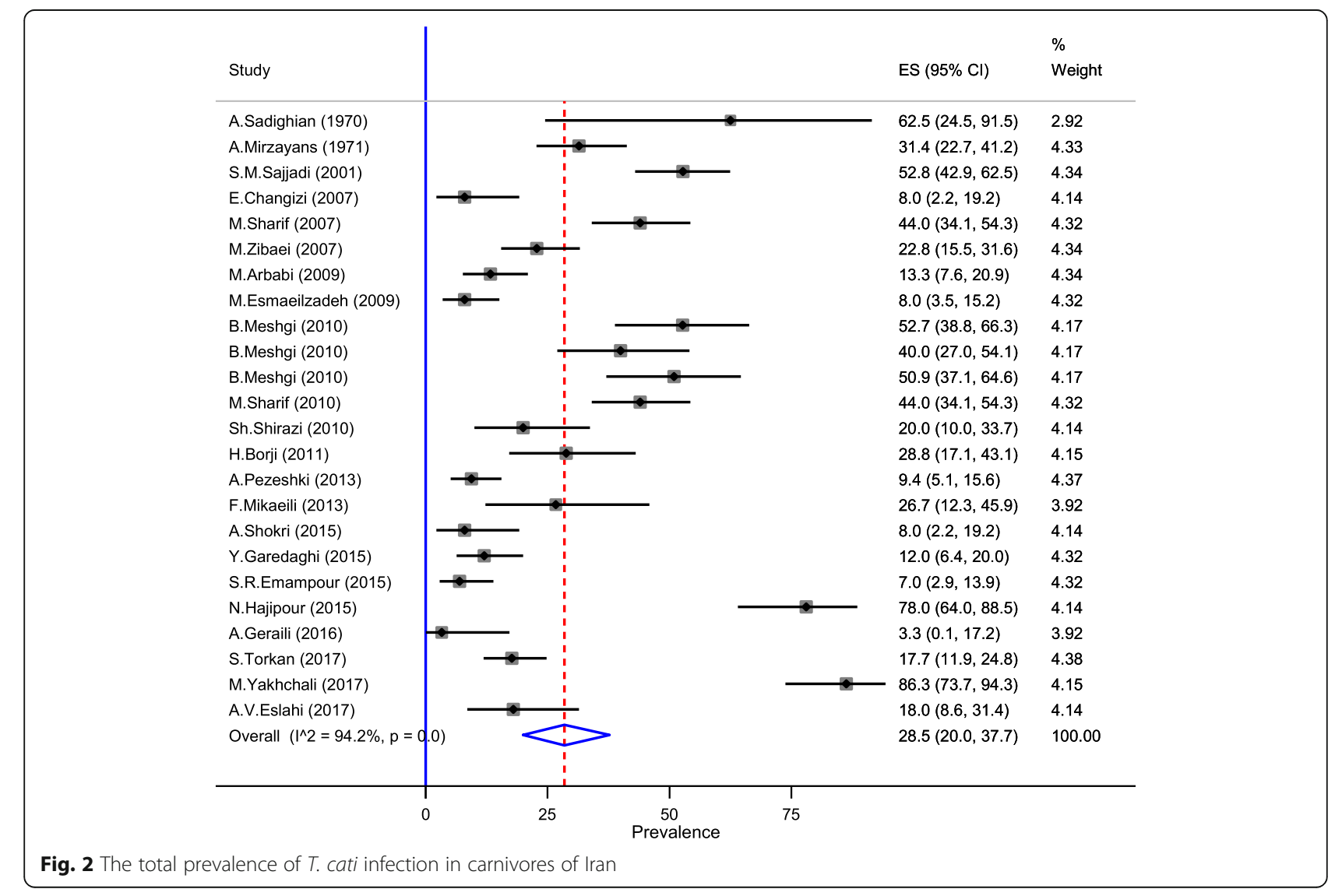




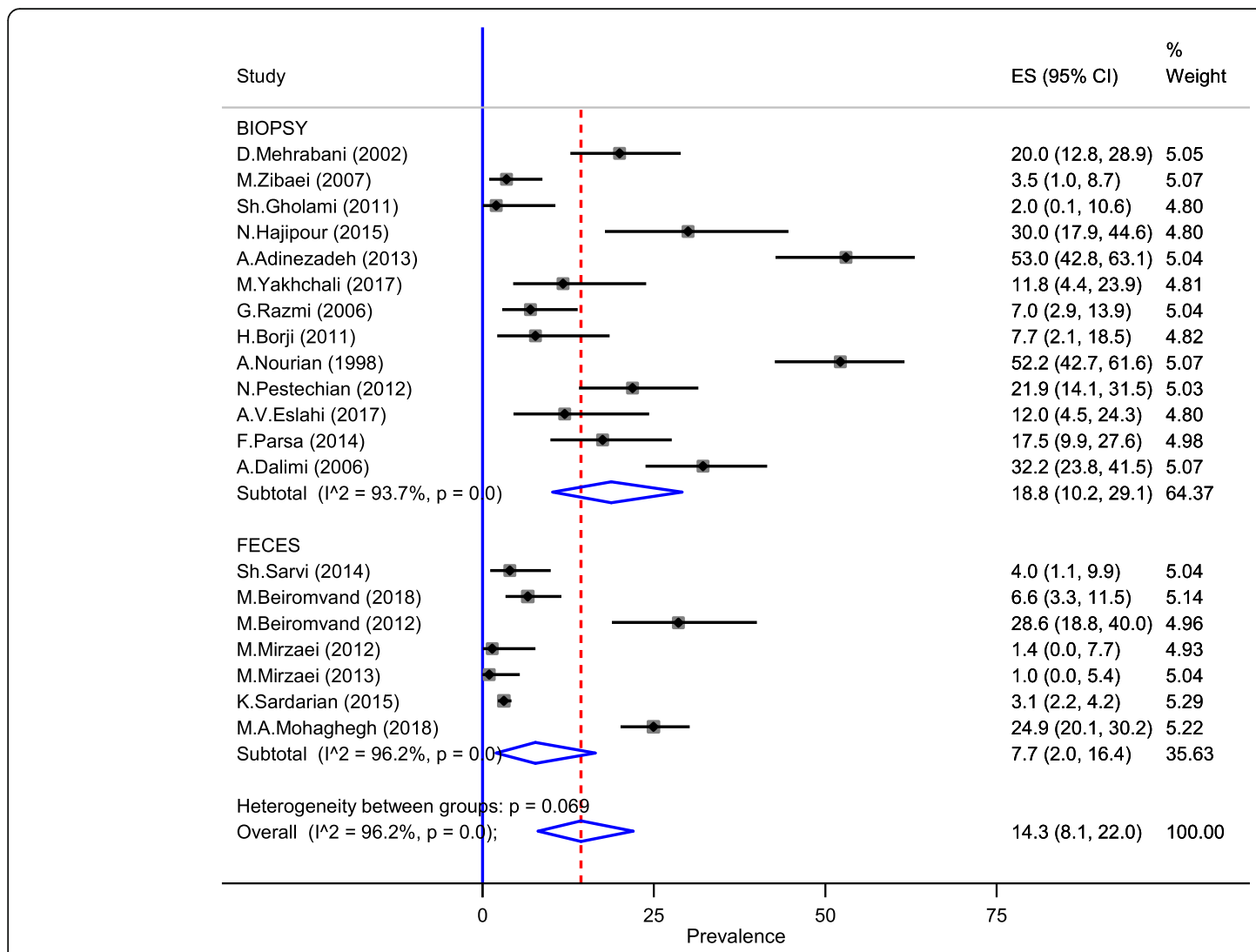

Fig. 3 The weighted prevalence of T. leonina in Iran carnivores by study method

geographical parameters comprising mean temperature, humidity, longitude and latitude (Fig. 8). Despite of equal records of Toxocara/Toxascaris infection from rural and urban areas, seroprevalence was partly elevated in urban regions rather than rural territories, resulting from the likely heterogeneity among studies and/or lack of sufficient records; care must be taken in interpreting such result as rural areas are naturally considered as higher risk areas than urban $[9,11,17,20]$.

Toxocariasis due to several species of Toxocara and/or Toxascaris roundworms is still a seriously notifiable public health issue, particularly due to its intricate transmission routes [25]. In human this infection is caused by $T$. canis, in particular, and T. cati renders several issues comprising VLM, OLM, NLM and covert disease, each of which is represented by manifestations of the involved organ [26, 27]. Toxocara/Toxascaris infection in human populations is considered as a chronic parasite in nature which is distributed worldwide, particularly in tropical underdeveloped countries [28]. Several risk factors are supposed to play a major role in Toxocara/Toxascaris distribution among the human population, consisting of habitation in rustic areas, soil contact, consuming the undercooked meat of the infected paratenic host, insufficient and unhygienic water repositories, poor housing and low education as well [29-32]. Furthermore, owing to the adventurous nature of children, such as tasting any objects, eating soil and/or earthworms and being in the vicinity of dogs and cats, they are considered as a substantial risk group regarding toxocariasis [4, 33]. Hence, public places in which children may walk around such as parks, playgrounds, beaches and sandboxes are crucial territories for the acquisition of the infection [28, 31]. Since most individuals do not manifest any pathognomonic symptoms, the actual prevalence rate of the infection remains to be elucidated, even in industrialized nations [34, 35]. Considering that Toxocara parasites do not develop into adult stage in humans, coproscopy is unnecessary; thus, biopsy and direct parasite observation are the gold standard methods [36]. However, such examination is invasive and relies on the larval load and the infection phase [28]. Therefore, routine diagnosis of infection and/or exposure in human cases can be done by ELISA to detect specific antibody against TES antigens, which should be further validated by immunoblotting [37, 38]. As previously mentioned, TES-based ELISA tests are mostly used for human seroprevalence studies. Despite having proper immunogenicity, native TES antigens may cross-react with antibodies elicited against other helminths specifically Ascaris lumbricoides 


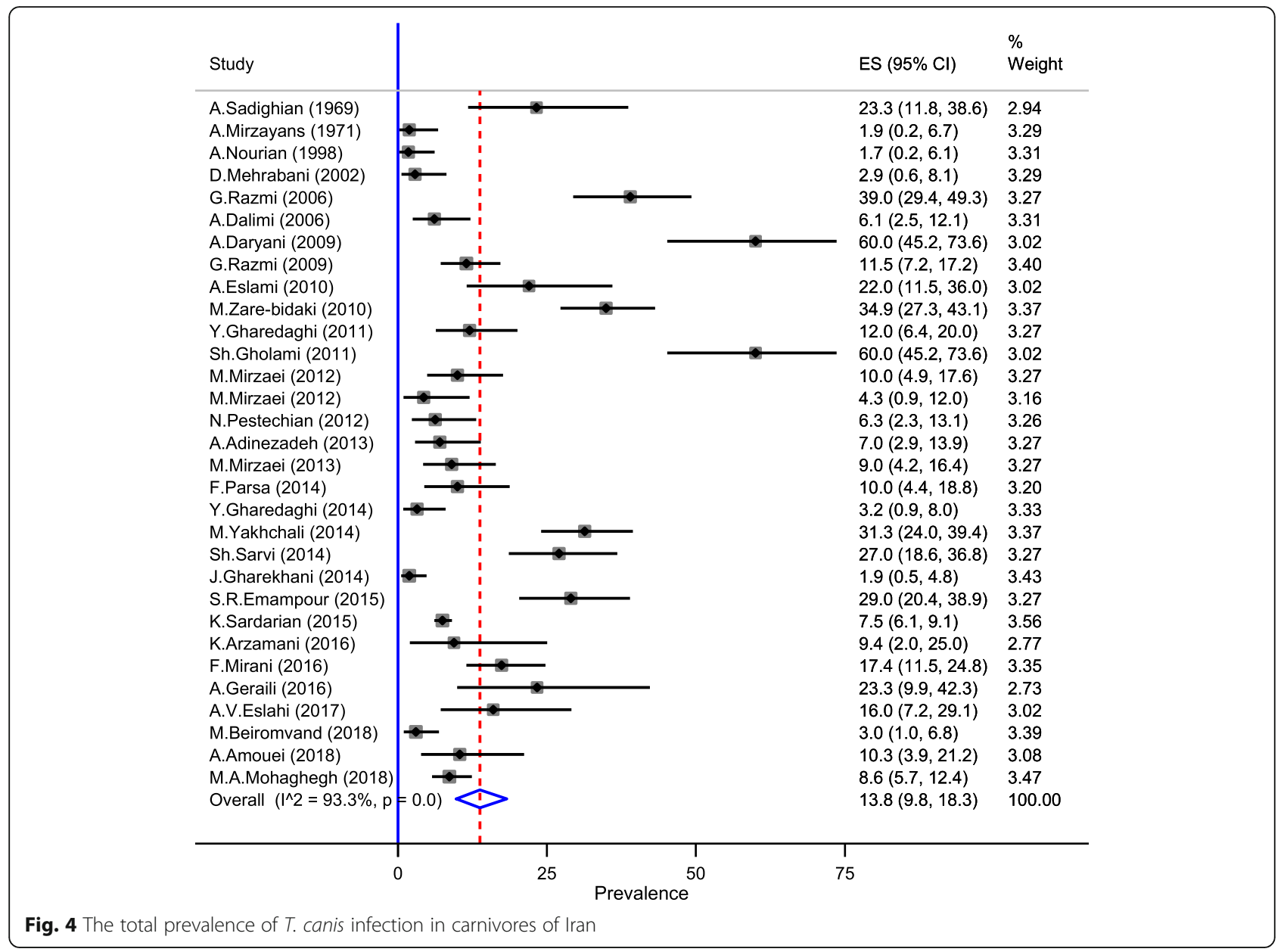

which decreases test specificity [39]. Therefore, the results may be regarded as suspicious, particularly when no immunoblotting confirmation is done, specifically in endemic regions where there exists the possibility of helminth co-infections. Alternative detection methods in paratenic or accidental hosts are including pathological inspection, larvae morphometry as well as PCR-based experiments [4]. A great deal of effort has been devoted to revealing the seroprevalence of human Toxocara/Toxascaris infection worldwide. In Africa, elevated seroprevalence rates of infection were detected, encompassing 6\% in Egypt to $60 \%$ in Gabon and $92 \%$ in Réunion Island $[5,40]$. Additionally, the seroprevalence ranges in Asia and South America included 11 -84.6\% and $7.3-66 \%$, respectively [41-43]. Comparable to other territories, rates of seropositive human cases were relatively low in European and North American countries [3], implicating improved hygiene practices and public awareness in industrialized nations.

In total, seroprevalence data integration in epidemiological investigations is not reasonable for several reasons, comprising sampling disparities, antigen preparation, and quality, different cutoff levels, cross-reactivity especially in the tropics were polyparasitism exist and inability to explicitly distinguish the infection by various Toxocara spp. Therefore, expanding our evidence based on human Toxocara infection would be corroborated by a better understanding of parasite biology, in particular, the immune evasion mechanism of larvae, and utilization of advanced, species-specific diagnostic tools [30].

The calculated total prevalence of infection in cats (Felis catus) was higher [32.6\% (95\% CI: 22.6-43.4\%)] than in dogs (Canis familiaris) [24.2\% (95\% CI: $18-$ $31 \%$ )] in the country (Table 1). Similar to human seropositive cases, carnivores in northern Iran were the most frequent hosts being parasitized by Toxocara spp., whereas minimum animals were infected in central parts [12\% (95\% CI: 8-17\%)]. Among wild canine species in Iran, only jackal (Canis aureus) and red fox (Vulpes vulpes) were diagnosed with Toxocara/Toxascaris infection, with $23.3 \%$ (95\% CI: 7.7-43.2\%) and 69.4\% (95\% CI: $60.3-77.8 \%$ ), respectively (Table 1 ).

Moreover, it was deduced that the weighted prevalence of T. canis, T. cati, and T. leonina in Iran were $13.8 \%$ (95\% CI: $9.8-18.3 \%), 28.5 \%$ (95\% CI: $20.0-37.7 \%$ ), and 14.3\% (95\% CI: 8.1-22.0\%), respectively. Given 


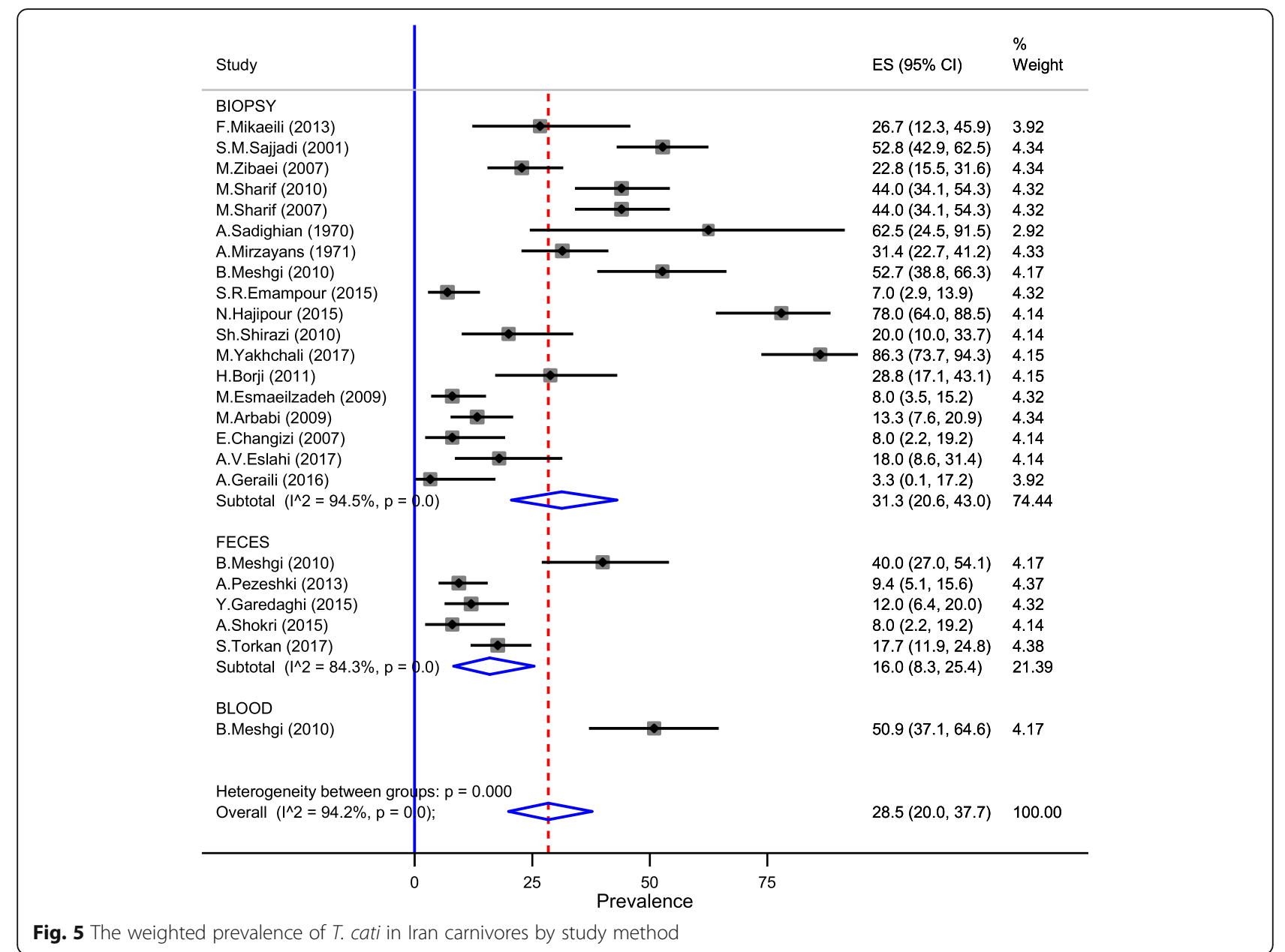

geographical characteristics, only humidity $(P=0.023)$ and latitude $(P=0.032)$ were significantly linked to $T$. canis infection. Increasing latitude would likely result in decreased mean temperature and more temperate climates than the equator area. Water vaporization and condensation in northern parts of the country due to the vicinity to the Caspian Sea and high mountain ranges and humid weather substantially implicate in Toxocaral Toxascaris larval development, as proved in the laboratory $[17,20]$.

The survey of the infection in carnivores is usually made via traditional parasitological methods (e.g. floatation technique) to detect eggs as well as intestinal necropsy of dead carcasses [44, 45]. Nevertheless, each detection method may provide a prevalence rate different from other modalities, which this issue would implicate potential biases in reporting and/or interpreting data. As we stated in the results section, necropsy has been shown as a better and efficient detection tool than fecal examination. For instance, more than 2-fold prevalence of Toxocara/Toxascaris spp. in dogs was obtained using necropsy [34.3\% (95\% CI $=26.4-42.8 \%)]$ than fecal examination $[15.6 \%(95 \% \mathrm{CI}=9.8-22.4 \%)]$. Also, necropsy was the most efficacious method in cats with $37.4 \%$ (95\% CI $=23.5-52.4 \%)$ than fecal examination $[20.4 \%(95 \% \mathrm{CI}=9.4-34.2 \%)]$. On an international scale, different studies have documented the prevalence of Toxocara/Toxascaris in stray/domestic dogs (Canis familiaris) and cats (Felis catus). In Europe, T. canis prevalence in dogs ranged from 1\% in Germany to $76 \%$ in Albania. Also, the prevalence of $T$. cati infection was up to $34.5 \%$ in Spain in this continent [46-49]. In dogs dwelling in the Americas, T. canis infection prevalence varied from $12.7 \%$ in Canadian provinces to $18 \%$ in Cuba. Also, T. cati was mostly prevailed in Argentina and Brazil with 61 and 25\%, respectively [50-53]. The highest $T$. canis and T. cati infection rates in Asia were dedicated to Russia and China with 63 and 36.5\%, respectively [54, 55]. Additionally, mild Toxocara species infections were identified in African domestic carnivores [56-59].

Globally, the highest T. leonina prevalence (up to 38\%) was observed in domestic dogs from Russia [52]. Wildlife probably plays a critical role in the epidemiology of 


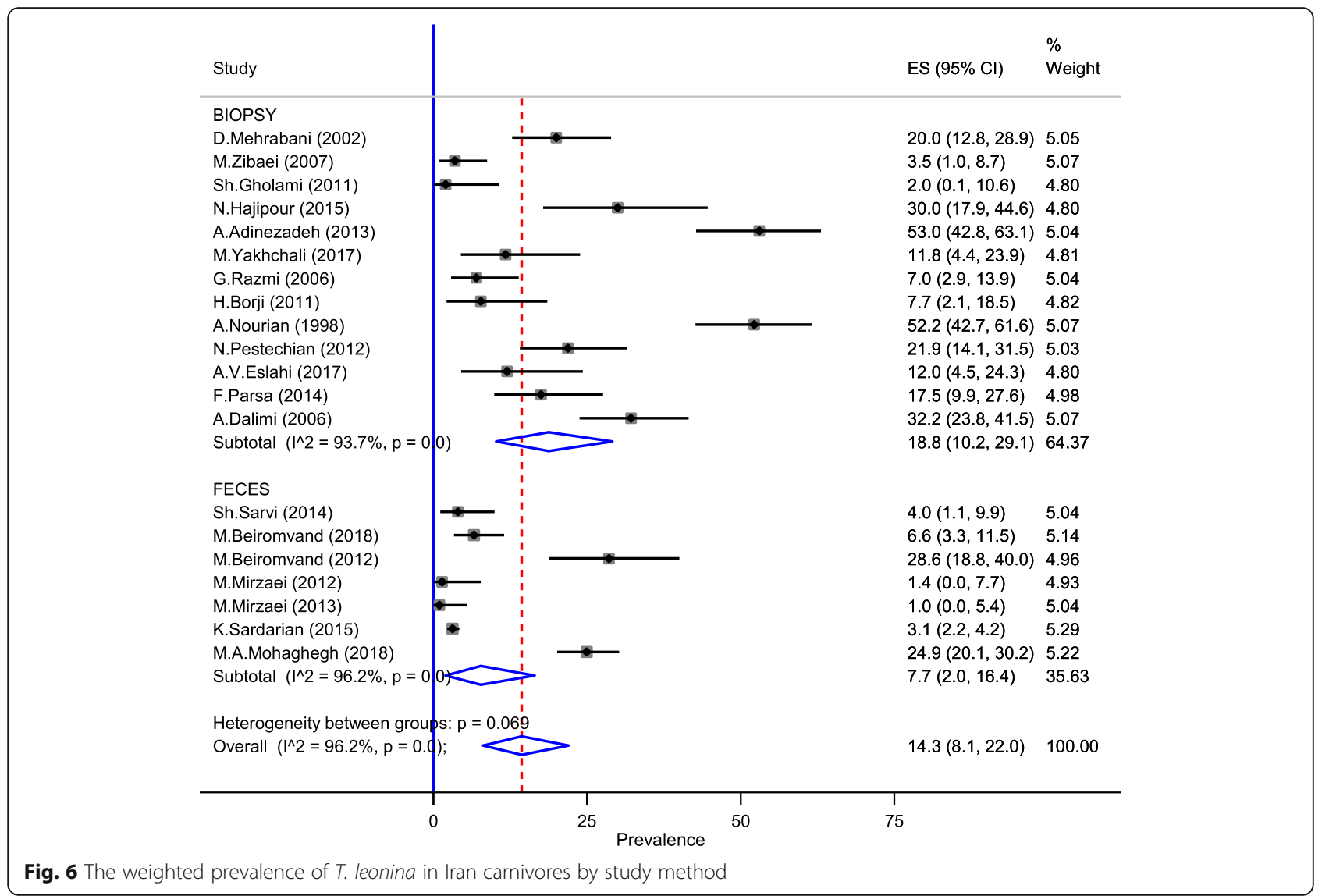

Toxocara species, as they may be considered as potent reservoir for these enigmatic roundworms [60].

Patent $T$. canis infections are generally higher in young foxes (under 6 months of age); although, a relatively high prevalence rate have also been among adult foxes in endemic territories, representing weak immune status against intestinal [61]. The prevalence of $T$. canis in European foxes varies between $9.0 \%$ (in Italy) and $65.0 \%$ (in Denmark), as well as 32.5 and $71.0 \%$ prevalence in Canada and Japan, respectively [61]. The lowest and highest $T$. leonina prevalence in red fox was reported from Kirghizstan (5.9\%) and the Slovak Republic (47.1\%), respectively [60]. Regarding golden jackal (Canis aureus) moderate prevalence rates of Toxascaris leonina have been reported around the world, such as in Azerbaijan (31.8\%), Bulgaria (36\%) and Russia (43.5\%). The prevalence of $T$. canis in this wildlife species ranges 40-61\% in Asia and 20-54.5\% in European countries, whereas $T$. cati was only detected in jackals dwelling in Russia (5-26\%) [49, 62]. Considering that there are only 4 golden jackal studies and 2 red fox (Vulpes vulpes) studies, there exist paucity of data on Toxocara/Toxascaris prevalence in wild canine and feline fauna of Iran, which highlights more subtle investigations.
Approximately, since the middle of previous century a periurban rise in European foxes population carrying Toxocara/Toxascaris worm burdens have posed a great environmental risk of contamination with parasite ova. On the other hand, they act a critical role in maintaining $T$. canis wildlife cycle with implications in constant transmission to human populations and pet dogs [63].

The findings of the present study indicated a mild seroprevalence in human population; also, infection in cats was higher than dogs, however unbalanced sampling may have influenced these findings. Most of the infected cases were from north of Iran, which possess a favorable ecological milieu for appropriate animal hosts and Toxocara egg development (i.e., $28-33^{\circ} \mathrm{C}$ in laboratory-based conditions, during 2-6 weeks [64]. Despite the improved hygiene and health surveillance systems as well as a wide-range public awareness in developed countries, still Toxocara/Toxascaris infection remains a public health concern in those areas and the rest of the world as well. During the time, there have been established a close companionship between dogs and cats with humans, and during past decades it has been even strengthened. However, these associations, particularly in underdeveloped nations, have been accompanied with poor 


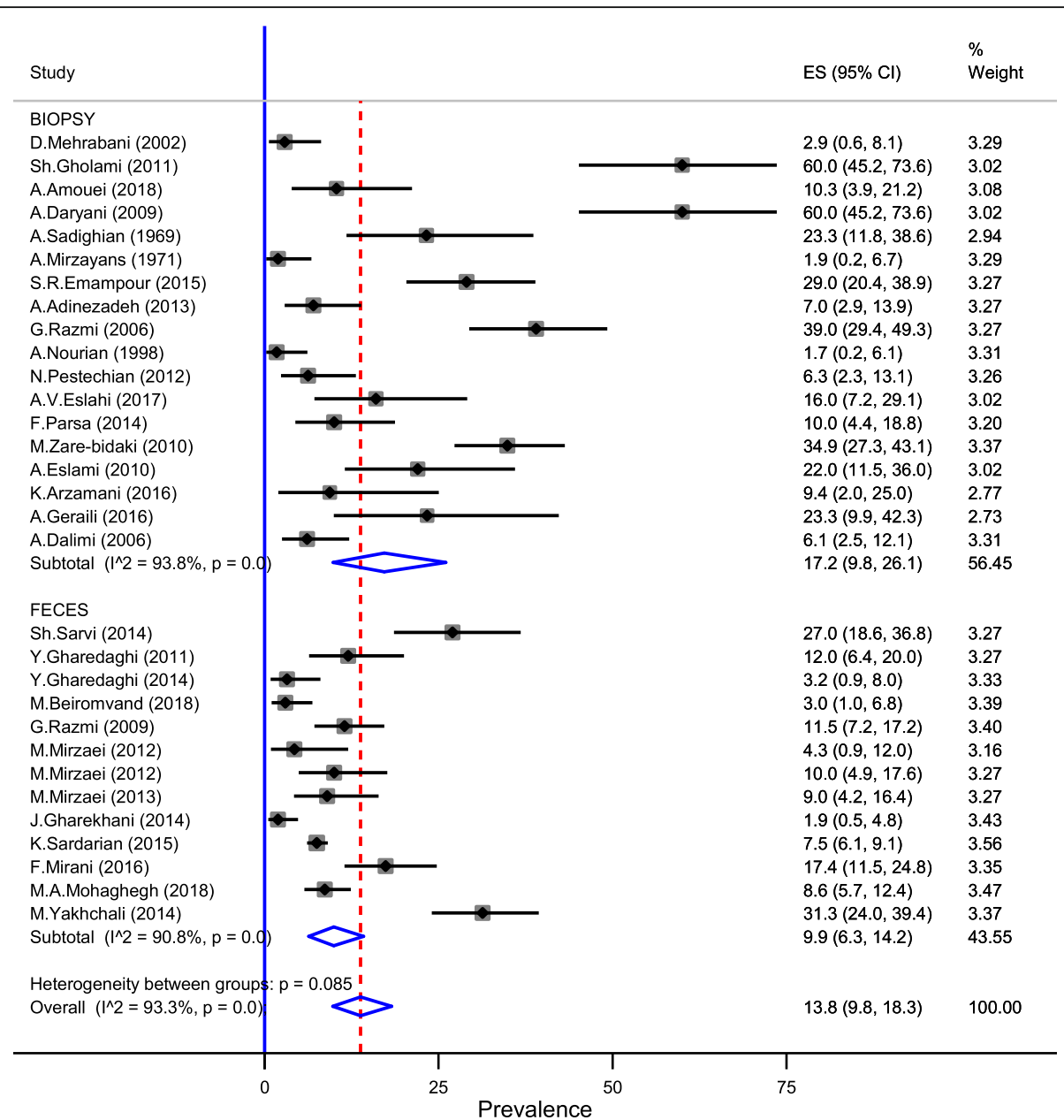

Fig. 7 The weighted prevalence of T.canis in Iran carnivores by study method

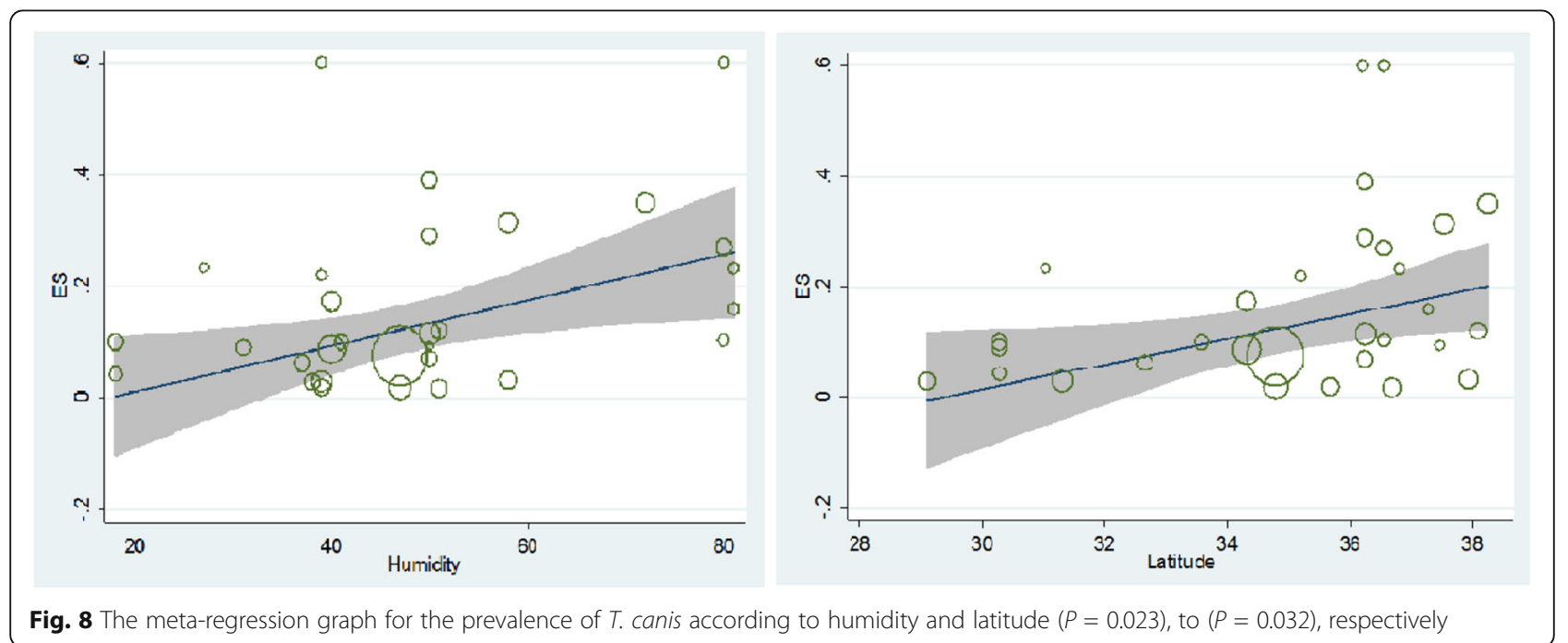

Fig. 8 The meta-regression graph for the prevalence of $T$. canis according to humidity and latitude $(P=0.023)$, to $(P=0.032)$, respectively 


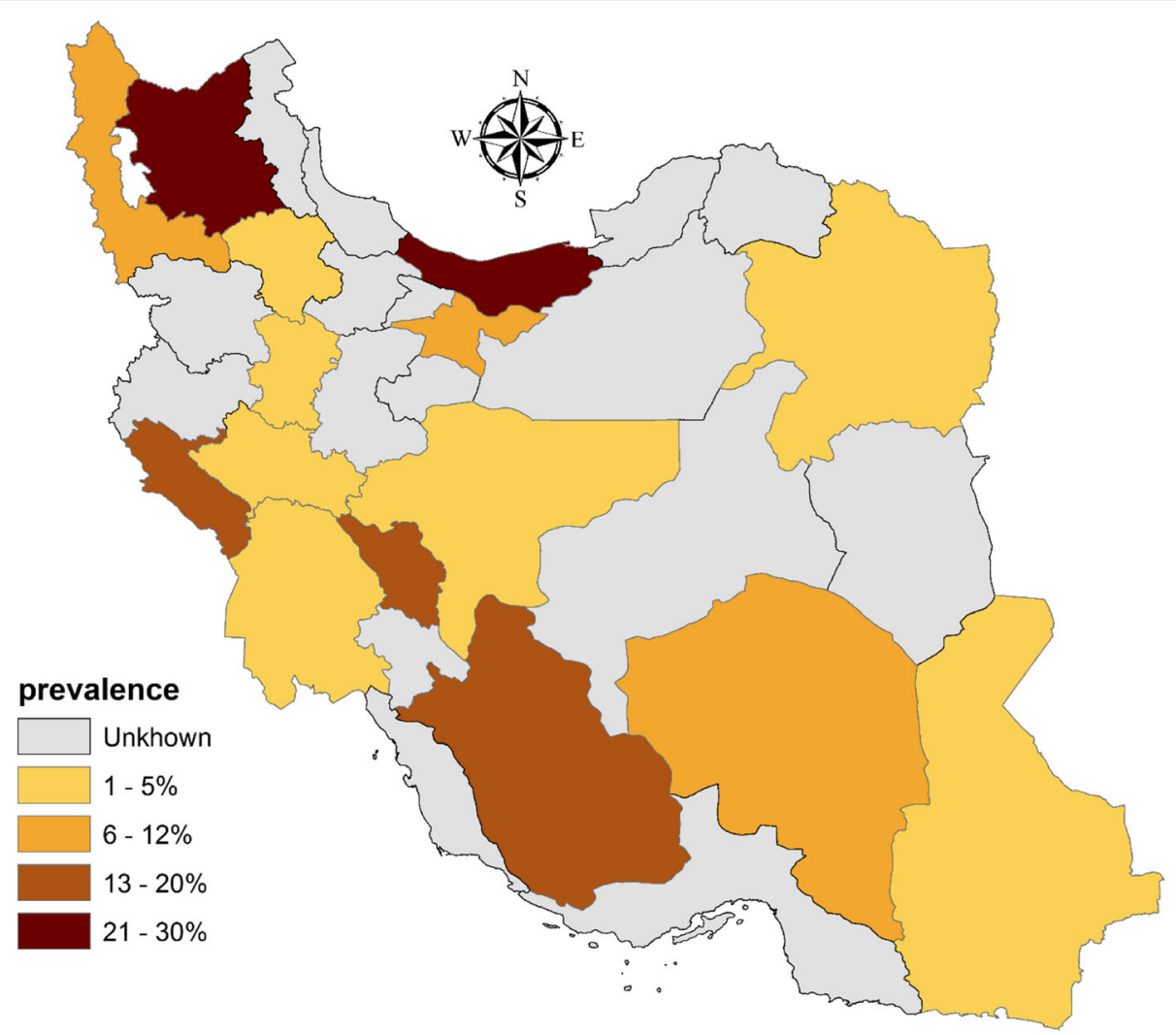

Fig. 9 Distribution map of human Toxocara/Toxascaris prevalence by province in Iran

veterinary infrastructures. This, along with free-roaming or community-owned dogs and cats pose a serious threat for zoonoses transmission to human societies [65].

With respect to the constant infection cycle in carnivores and the life-threatening traits of human toxocariasis, revisiting the epidemiological strategies in companion animals enclosing anti-helminthic medication and screening plans such as the routine fecal examination is of utmost importance. In addition, it is highly emphasized that future human investigations focus on using recombinant TES antigens with high sensitivity and specificity and less cross-reactivity. Also, it is better to identify anti-Toxocara IgG $_{4}$ coupled with TES rather than total IgG and employ western blot as a complementary diagnostic technique [28]. Moreover, it is recommended to educate laboratory technicians for accurate parasite detection, regularly deworm puppies and kittens to decrease the worm burden, perform proactive chemoprophylaxis approach and cultivate knowledge among the public as well as physicians regarding the clinical consequences of the disease. The interwoven collaboration among blood banks, veterinary diagnostic laboratories and municipalities (control stray dog/cat populations in urban areas) would provide a more completed picture of disease seroprevalence and distribution in people and animals, giving us the opportunity for targeted intervention strategies and better management of this zoonotic enigma. In parallel to above-mentioned recommendations the WSAVA has recently found a One Health Committee to highlight the transmission potential of zoonotic infectious agents from dog/cat to human. Besides the OIE has recently extended the surveillance of wildlife diseases through WAHID in the world. All of these expanded fields of epidemilogical data would assist the global community towards better understanding of human-domestic animal-wildlife interplay and control of human zoonotic diseases [63].

\section{Limitations}

It is noteworthy to mention that some limitations constrained our findings en route performing current systematic review and meta-analysis, including 1) lack of risk factor appraisal, 2) absence of a standard, easy-touse diagnostic tool in case of human studies to particularly discern the involved Toxocara spp., 3) lack of investigations considering different aspects of human Toxocara-induced complications such as VLM, OLM, and covert infection. Certainly, with these in hands, we could achieve the more complete picture of the current 
situation of Toxocara/Toxascaris infection in animal and human hosts of Iran.

\section{Conclusion}

In conclusion, this study revealed that Toxocara and Toxascaris infection in Iran among people is mild while in dogs and cats are high. Exclusive studies including human, animal and environmental health data should be conducted in different geographical regions of the country. The outcome of such studies will allow the government and non-government organization to set proprieties and design strategies, combining accurate surveillance and prevention of these zoonotic diseases.

\section{Supplementary information}

Supplementary information accompanies this paper at https://doi.org/10 1186/s12879-020-4759-8.

Additional file 1: Figure S1. The quality assessment of included studies of human population

Additional file 2: Figure S2. The weighted prevalence of human Toxocara/Toxascaris by the year in Iran

Additional file 3: Figure S3. The weighted prevalence of human Toxocara/Toxascarisby the age in Iran

Additional file 4: Figure S4. The weighted prevalence of Toxocaral Toxascaris in Iran dogs by study method

Additional file 5: Figure S5. The total prevalence of $T$. canis in feces of animals according to the different parasitology methodsin carnivore population in Iran.

Additional file 6: Figure S6. The total prevalence of $T$. cati in feces according to the different parasitology methods in carnivore population in Iran

\section{Abbreviations}

Cl: Confidence interval; ELISA: Enzyme-linked immunosorbent assay IgE: Immunoglobulin E; IgG: Immunoglobulin G; IL: Interleukin; JBI: Joanna Briggs Institute; NLM: Neural larva migrans; OlE: Organization for Animal Health; OLM: Ocular larva migrans; PCR: Polymerase chain reaction; SID: Scientific information database; STATA: Statistics and data; T. canis: Toxocara canis; T. cati: Toxocara cati; T. leonina: Toxascaris leonina; TES: Toxocara excretory-secretory; Th: T-helper; VLM: Visceral larva migrans; WAHID: World Animal Health Information Database; WSAVA: World Small Animal Veterinary Association

\section{Acknowledgments}

The authors would like to thank all staff of the Department of Parasitology of Tarbiat Modares University and Alborz University of Medical Sciences, Iran.

\section{Authors' contributions}

AVE, MB and $M Z$ designed the study. AVE, MB, HM, EH, HH, AT, MF, NP searched for primary publications, screened and appraised primary studies. $M B, F F$, and $M Z$ extracted the data and wrote the study manuscript. AK and SMR contributed to data analysis and interpretation the manuscript. All authors read the manuscript and participated in the preparation of the final version of the manuscript. All authors read and approved the final manuscript.

\section{Funding}

There was no any funding or sponsoring organization for this review.

\section{Availability of data and materials}

The datasets used and analyzed during the current study are available from the corresponding author on reasonable request.

\section{Ethics approval and consent to participate}

The study design including its ethical aspects was reviewed and approved by the Ethics Committee of Alborz University of Medical Sciences.

Consent for publication

Not applicable.

\section{Competing interests}

The authors declare that they have no competing interests.

\section{Author details}

${ }^{1}$ Department of Parasitology, Faculty of Medical Sciences, Tarbiat Modares University, Tehran, Iran. ${ }^{2}$ Department of Epidemiology, School of Medicine, Ilam University of Medical Sciences, Ilam, Iran. ${ }^{3}$ Department of Parasitology, Faculty of Veterinary Medicine, Rasht Branch, Islamic Azad University, Rasht, Iran. ${ }^{4}$ Department of Parasitology and Mycology, School of Medicine, Alborz University of Medical Sciences, 3149779453, Karaj, Iran. ${ }^{5}$ Abadan Faculty of Medical Sciences, Abadan, Iran. 'Department of Parasitology and Mycology, School of Medicine, Isfahan University of Medical Sciences, Isfahan, Iran. ${ }^{7}$ Infectious Diseases and Tropical Medicine Research Center, Isfahan University of Medical Sciences, Isfahan, Iran. ${ }^{8}$ Department of Microbiology, School of Medicine, Alborz University of Medical Sciences, Karaj, Iran. ${ }^{9}$ Department of Epidemiology and Biostatistics, School of Health, Birjand University of Medical Sciences, Birjand, Iran. ${ }^{10}$ Evidence-based Phytotherapy and Complementary Medicine Research Center, Alborz University of Medical Sciences, Karaj, Iran

Received: 3 June 2019 Accepted: 31 December 2019

Published online: 07 January 2020

\section{References}

1. Neo JPS, Tan BH. The use of animals as a surveillance tool for monitoring environmental health hazards, human health hazards and bioterrorism. Vet Microbiol. 2017;203:40-8

2. Berrett AN, Erickson LD, Gale SD, Stone A, Brown BL, Hedges DW. Toxocara seroprevalence and associated risk factors in the United States. Am J Trop Med Hyg. 2017:97(6):1846-50.

3. Lee RM, Moore LB, Bottazzi ME, Hotez PJ. Toxocariasis in North America: a systematic review. PLoS Negl Trop Dis. 2014;8(8):e3116.

4. Macpherson CN. The epidemiology and public health importance of toxocariasis: a zoonosis of global importance. Int J Parasitol. 2013;43 (12-13):999-1008.

5. Lötsch F, Vingerling R, Spijker R, Grobusch MP. Toxocariasis in humans in Africa-a systematic review. Travel Med Infect Dis. 2017:20:15-25.

6. Strube C, Heuer L, Janecek E. 2013. Toxocara spp. infections in paratenic hosts. Vet Parasitol. 2013;193(4):375-89.

7. Zibaei M, Sadjjadi SM, Jahadi-Hosseini SH. Toxocara cati larvae in the eye of a child: a case report. Asian Pac J Trop Biomed. 2014:4(Suppl 1):S53-5.

8. Woodhall DM, Eberhard ML, Parise ME. Neglected parasitic infections in the United States: toxocariasis. Am J Trop Med Hyg. 2014;90(5):810-3.

9. Aghamolaie S, Seyyedtabaei SJ, Behniafar H, Foroutan M, Saber V, Hanifehpur $\mathrm{H}$, et al. Seroepidemiology, modifiable risk factors and clinical symptoms of Toxocara spp. infection in northern Iran. Trans $\mathrm{R}$ Soc Trop Med Hyg. 2019;113(3):116-22.

10. Zibaei M. Helminth infections and cardiovascular diseases: Toxocara species is contributing to the disease. Curr Cardiol Rev. 2017;13(1):56-62.

11. Badri M, Kiani Z, Faridnia R, Mousavi M, Mehrabi H, Pestechian N, et al. Effect of Toxocara canis and Toxascaris leonina egg antigens on induction of eosinophilia in animal model. J Shahrekord Uuniv Med Sci. 2014:16(4):95-9.

12. Zibaei M, Shayesteh Z, Moradi N, Bahadory S. Human Toxocara infection: allergy and immune responses. Antiinflamm Antiallergy Agents Med Chem. 2019;18(2):82-90.

13. de Ruiter K, Tahapary D, Wammes L, Wiria A, Hamid F, van Lieshout L, et al. The effect of three-monthly albendazole treatment on Th2 responses: differential effects on IgE and IL-5. Parasite Immunol. 2017;39(6):e12428.

14. Choobineh M, Mikaeili F, Sadjjadi SM, Ebrahimi S, Iranmanesh S. Molecular characterization of Toxocara spp. eggs isolated from public parks and playgrounds in shiraz, Iran. J Helminthol. 2019;93(3):306-12.

15. Mikaeili F, Mirhendi H, Hosseini M, Asgari Q, Kia EB. Toxocara nematodes in stray cats from shiraz, southern Iran: intensity of infection and molecular identification of the isolates. Iran J Parasitol. 2013;89(4):593-600. 
16. Tavassoli M, Tadayon K. Studies on Toxocara vitulorum infection of native and dairy calves in Urmia, Iran. J Fac Vet Med Univ Tehran. 2000;55(1):71-3.

17. Maleki B, Khorshidi A, Gorgipour M, Mirzapour A, Majidiani H, Foroutan M. Prevalence of Toxocara spp. eggs in soil of public areas in Iran: a systematic review and meta-analysis. Alexandria J Med. 2018;54:97-101.

18. Zibaei M, Alemi M, Marina Cardillo N, Derafshi H, Miahipour A, Bahadory S, Zarei M. Human toxocariasis seroprevalence among patients with uveitis in Alborz Province, Iran. Ann Agric Environ Med. 2019;26(1):154-8.

19. Badri M, Eslahi AV, Majidiani H, Pirestani M. Spirometra erinaceieuropaei in a wildcat (Felis silvestris) in Iran. Vet Parasitol Reg Stud Reports. 2017;10:58-61.

20. Eslahi AV, Kia EB, Mobedi I, Sharifdini M, Badri M, Mowlavi G. Road killed carnivores illustrate the status of zoonotic helminthes in Caspian Sea littoral of Iran. Irani J Parasitol. 2017;12(2):230-5.

21. Foroutan M, Rostami A, Majidiani H, Riahi SM, Khazaei S, Badri M, et al. A systematic review and meta-analysis of the prevalence of toxoplasmosis in hemodialysis patients in Iran. Epidemiol Health. 2018;40:e2018016.

22. Moher D, Liberati A, Tetzlaff J, Altman DG. Preferred reporting items for systematic reviews and meta-analyses: the PRISMA statement. Int I Surg. 2010;8(5):336-41.

23. Aromataris E, Fernandez R, Godfrey CM, Holly C, Khalil H, Tungpunkom P. Summarizing systematic reviews: methodological development, conduct and reporting of an umbrella review approach. Int J Evid Based Healthc. 2015;3(3):132-40.

24. Higgins J, Thompson SG. Quantifying heterogeneity in a meta-analysis. Stat Med. 2002;21(11):1539-58.

25. Rubinsky-Elefant G, Hirata CE, Yamamoto JH, Ferreira MU. 2010. Human toxocariasis: diagnosis, worldwide seroprevalences and clinical expression of the systemic and ocular forms. Ann Trop Med Parasitol. 2010;104(1):3-23.

26. Fisher M. Toxocara cati: an underestimated zoonotic agent. Trends Parasitol. 2003:19(4):167-70

27. Smith H, Holland C, Taylor M, Magnaval J, Schantz P, Maizels R. How common is human toxocariasis? Towards standardizing our knowledge. Trends Parasitol. 2009;25(4):182-8

28. Moreira GMSG, de Lima TP, Mendonça M, Moreira ÂN, McBride AJA, Scaini CJ, Conceição FR. Human toxocariasis: current advances in diagnostics, treatment, and interventions. Trends Parasitol. 2014:30(9):456-64.

29. Aghaei S, Riahi SM, Rostami A, Mohammadzadeh I, Javanian M, Tohidi E, Foroutan M, Dooki ME. Toxocara spp. infection and risk of childhood asthma: a systematic review and meta-analysis. Acta Trop. 2018;182:298-304.

30. Ma G, Holland CV, Wang T, Hofmann A, Fan CK, Maizels RM, et al. Human toxocariasis. Lancet Infect Dis. 2017;18(1):e14-24.

31. Zibaei M, Abdollahpour F, Birjandi M, Firoozeh F. Soil contamination with Toxocara spp. eggs in the public parks from three areas of Khorram Abad, Iran. Nepal Med Coll J. 2010;12(2):63-5.

32. Zibaei M, Sadjjadi SM, Maraghi S. The occurrence of Toxocara species in naturally infected broiler chickens revealed by molecular approaches. J Helminthol. 2017:11(7):557-62.

33. Zibaei M, Sadjjadi SM, Sarkari B. Prevalence of Toxocara cati and other intestinal helminths in stray cats in shiraz, Iran. Trop Biomed. 2007:24(2):39-43.

34. Weaver RJ, Santos ESA, Tucker AM, Wilson AE, Hill GE. Carotenoid metabolism strengthens the link between feather coloration and individual quality. Nat Commun. 2018;9(1):73.

35. Hotez PJ, Wilkins PP. Toxocariasis: America's most common neglected infection of poverty and a helminthiasis of global importance? PLoS Negl Trop Dis. 2009;3(3):e400.

36. Zibaei M, Sadjjadi SM, Uga S. Experimental Toxocara cati infection in gerbils and rats. Korean J Parasitol. 2010:48(4):331-3.

37. Zibaei M, Sadjjadi SM, Karamian M, Uga S, Oryan A, Jahadi-Hosseini SH. A comparative histopathology, serology and molecular study, on experimental ocular toxocariasis by Toxocara cati in Mongolian gerbils and Wistar rats. Biomed Res Int. 2013;2013:109580.

38. Zibaei M, Sadjjadi SM, Sarkari B, Uga S. Evaluation of Toxocara cati excretorysecretory larval antigens in serodiagnosis of human toxocariasis. J Clin Lab Anal. 2016:30(3):248-53.

39. Yamasaki H, Araki K, Lim PKC, Zasmy N, Mak JW, Taib R, et al. Development of a highly specific recombinantToxocara canis second-stage larva excretory-secretory antigen for immunodiagnosis of human toxocariasis. J Clin Microbiol. 2000:38(4):1409-13.

40. Lötsch F, Obermüller M, Mischlinger J, Mombo-Ngoma G, Groger M, Adegnika AA, et al. Seroprevalence of Toxocara spp. in a rural population in Central African Gabon. Parasitol Int. 2016;65(6):632-4.
41. Hayashi E, Tuda J, Imada M, Akao N, Fujita K. The high prevalence of asymptomatic Toxocara infection among schoolchildren in Manado, Indonesia. Southeast Asian J. trop. Med. Public Health. 2005;36(6):1399-406.

42. Torgerson PR, Rosenheim K, Tanner I, Ziadinov I, Grimm F, Brunner M, et al. Echinococcosis, toxocarosis and toxoplasmosis screening in a rural community in eastern Kazakhstan. Tropical Med Int Health. 2009;14(3):341-8.

43. Bolivar-Mejia A, Alarcón-Olave C, Calvo-Betancourt LS, Paniz-Mondolfi A, Delgado O, Rodriguez-Morales AJ. 2014. Toxocariasis in the Americas: burden and disease control. Curr Trop Med Rep. 2014;1(1):62-8.

44. Luty T. Prevalence of species of Toxocara in dogs, cats and red foxes from the Poznan region, Poland. J Helminthol. 2001;75(1):153-6.

45. Zibaei M, Sadjjadi S. Trend of toxocariasis in Iran: a review on human and animal dimensions. Iran J Vet Res. 2017;18(4):233-42.

46. Millán J, Casanova JC. High prevalence of helminth parasites in feral cats in Majorca Island (Spain). Parasitol Res. 2009:106(1):183-8.

47. Xhaxhiu D, Kusi I, Rapti D, Kondi E, Postoli R, Rinaldi L, et al. Principal intestinal parasites of dogs in Tirana, Albania. Parasitol Res. 2001;108(2):341-53.

48. Becker AC, Rohen M, Epe C, Schnieder T. Prevalence of endoparasites in stray and fostered dogs and cats in northern Germany. Parasitol Res. 2012;111(2):849-57.

49. Chalkowski K, Wilson AE, Lepczyk CA, Zohdy S. Who let the cats out? A global meta-analysis on risk of parasitic infection in indoor versus outdoor domestic cats (Felis catus). Biol Lett. 2019:15(4):20180840.

50. Labarthe N, Serrão ML, Ferreira AMR, Almeida NK, Guerrero J. A survey of gastrointestinal helminths in cats of the metropolitan region of Rio de Janeiro, Brazil. Vet Parasitol. 2004;123(13):133-9.

51. Sommerfelt I, Cardillo N, López C, Ribicich M, Gallo C, Franco A. Prevalence of Toxocara cati and other parasites in cats' faeces collected from the open spaces of public institutions: Buenos Aires, Argentina. Vet Parasitol. 2006; 140(3-4):296-301.

52. Sariego I, Kanobana K, Rojas L, Speybroeck N, Polman K, Núñez FA. Toxocariasis in Cuba: a literature review. PLoS Negl Trop Dis. 2012;6(2):e1382.

53. Villeneuve A, Polley L, Jenkins E, Schurer J, Gilleard J, Kutz S, et al. Parasite prevalence in fecal samples from shelter dogs and cats across the Canadian provinces. Parasit Vectors. 2015:8:281

54. Chen J, Xu M-J, Zhou DH, Song HQ, Wang CR, Zhu XQ. Canine and feline parasitic zoonoses in China. Parasit Vectors. 2012;5:152.

55. Moskvina T, Ermolenko A. Helminth infections in domestic dogs from Russia. Vet World. 2016;9(11):1248-58.

56. Mukaratirwa S, Singh V. Prevalence of gastrointestinal parasites of stray dogs impounded by the Society for the Prevention of cruelty to animals (SPCA), Durban and coast, South Africa. J S Afr Vet Assoc. 2010;81(2):123-5.

57. Swai $E$, Kaaya E, Mshanga D, Mbise E. A survey on gastro-intestinal parasites of non-descript dogs in and around Arusha Municipality, Tanzania. Int J Anim Vet Adv. 2010:2(3):63-7.

58. Zewdu E, Semahegn Y, Mekibib B. Prevalence of helminth parasites of dogs and owners awareness about zoonotic parasites in ambo town, Central Ethiopia. Ethiop Vet J. 2010;14(2):17-30.

59. Okoye I, Obiezue N, Okorie C, Ofoezie I. Epidemiology of intestinal helminth parasites in stray dogs from markets in South-Eastern Nigeria. J Helminthol. 2011:85(4):415-20.

60. Okulewicz A, Perec-Matysiak A, Buńkowska K, Hildebrand J. Toxocara canis, Toxocara cati and Toxascaris leonina in wild and domestic carnivores. Helminthologia. 2012;49(1):3-10.

61. Otranto D, Deplazes P. Zoonotic nematodes of wild carnivores. Int Parasitol Parasites Wildl. 2019:9:370-83.

62. Gherman CM, Mihalca AD. A synoptic overview of golden jackal parasites reveals high diversity of species. Parasit Vectors. 2017;10(1):419.

63. Scott DM, Berg MJ, Tolhurst BA, Chauvenet ALM, Smith GC, Neaves K, et al. Changes in the distribution of red foxes (Vulpes vulpes) in urban areas in Great Britain: findings and limitations of a media-driven nationwide survey. PLoS One. 2014:9(6):e99059.

64. Deplazes P, Eckert J, von Samson-Himmelstjerna G, Zahner H. Lehrbuch der Parasitologie für die Tiermedizin [textbook of parasitology for veterinary medicine]. Third Edition. Acta Vet Hung. 2013;61(1):147-8.

65. Day MJ, Breitschwerdt E, Cleaveland S, Karkare U, Khanna C, Kirpensteijn J, et al. Surveillance of zoonotic infectious disease transmitted by small companion animals. Emerg Infect Dis. 2012;18(12):e1.

\section{Publisher's Note}

Springer Nature remains neutral with regard to jurisdictional claims in published maps and institutional affiliations. 